\author{
Xavier Repessé \\ Siu-Ming Au \\ Cyril Charron \\ Antoine Vieillard-Baron
}

\section{Kaposi's sarcoma: a reversible cause of ARDS in HIV-infected patient}

Received: 14 February 2013

Accepted: 28 February 2013

Published online: 20 March 2013

(C) Springer-Verlag Berlin Heidelberg and ESICM 2013

X. Repessé · S.-M. Au · C. Charron · A. Vieillard-Baron Assistance Publique-Hôpitaux de Paris,

Boulogne-Billancourt 92100, France

\section{Repessé · S.-M. Au · A. Vieillard-Baron \\ University of Versailles Saint-Quentin en Yvelines, \\ Saint-Quentin en Yvelines 78280, France}

\section{Repessé ( $\bullet)$}

Intensive Care Unit, Section Thorax-Vascular Disease-AbdomenMetabolism, University Hospital Ambroise Paré, 9, avenue

Charles-de-Gaulle, Boulogne-Billancourt 92100, France

e-mail: xavier.repesse@apr.aphp.fr

Tel.: +33-1-4909903

Fax: +33-1-49095892

A 38-year-old untreated human immunodeficiency virus (HIV)-infected transsexual female was admitted to our intensive care unit (ICU) for acute respiratory distress syndrome (ARDS). She had no fever and no other organ failure at admission. Leukocyte count was $10.2 \mathrm{~g} / \mathrm{L}$,
C-reactive protein (CRP) was $135 \mathrm{mg} / \mathrm{L}$, serum procalcitonin was $0.11 \mu \mathrm{g} / \mathrm{L}, \mathrm{CD} 4$ count was $180 / \mathrm{mm}^{3}$, and lactate dehydrogenase (LDH) level was $625 \mathrm{UI} / \mathrm{L}$ $(N<626 \mathrm{UI} / \mathrm{L})$. Chest $\mathrm{X}$-ray and thoracic computed tomography (Fig. 1a) revealed diffuse alveolo-interstitial pulmonary lesions associated with pseudotumoral nodules visualized at bronchoscopy. Gastrointestinal endoscopy showed typical "cherry-red" lesions (Fig. 1b). Skin lesion biopsies confirmed the diagnosis of Kaposi's sarcoma (KS). The patient fully recovered after chemotherapy and was discharged from hospital 8 weeks later. KS is known as a lymphoproliferative disorder related to human herpesvirus 8 (HHV8) occurring in HIV-infected patients [1]. KS usually presents as extensive papular-nodular skin lesions [2]. ARDS has become a rare complication of KS thanks to the widespread use of highly active antiretroviral therapy (HAART) [2] and is described to occur without typical skin lesions in $15 \%$ of the pulmonary forms [3]. Low LDH level, negative serum procalcitonin, and CD4 count over $50 / \mathrm{mm}^{3}$ make other opportunistic infections unlikely [3]. Thoracic computed tomography is characterized by striking flame-shaped opacities and spicular thickening of the bronchovascular bundles [4]. HAART is the cornerstone of treatment [5], but severe clinical presentations can require chemotherapy, such as anthracyclines or paclitaxel [5].

Conflicts of interest On behalf of all authors, the corresponding author states that there is no conflict of interest. 

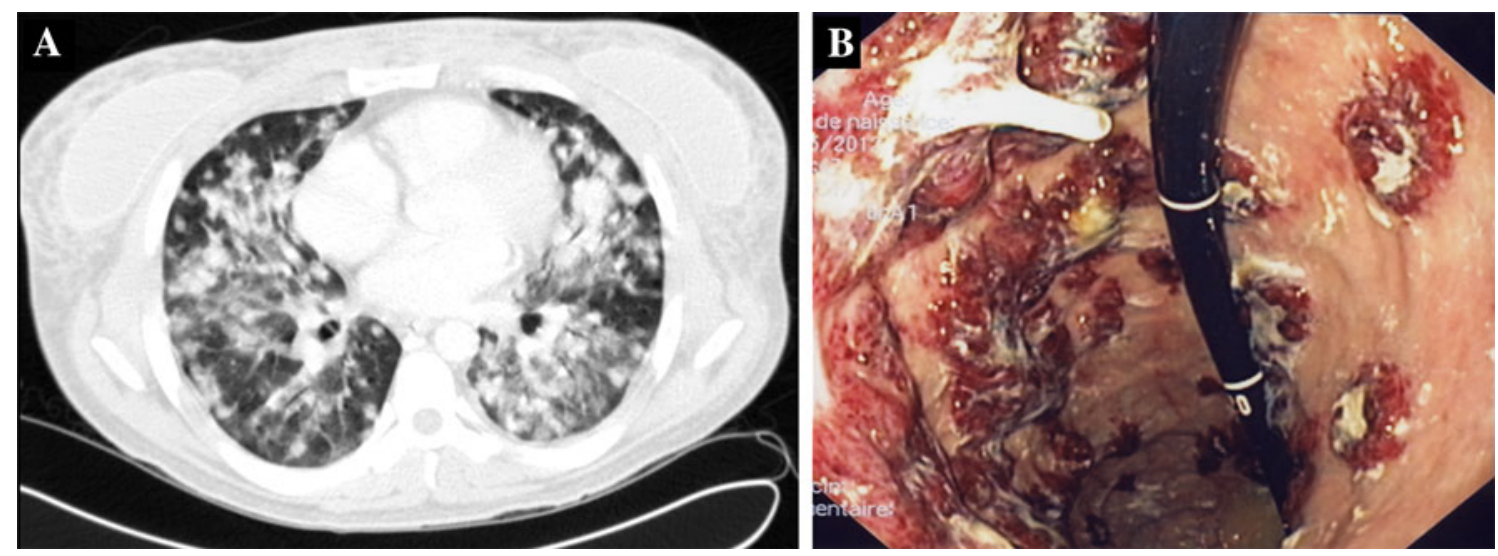

Fig. 1 a Thoracic computed tomography showing diffuse alveolo-interstitial pulmonary lesions associated with pseudotumoral aspect. b Gastric endoscopy revealing wide gastroesophageal spread of Kaposi sarcoma with typical "cherry-red" tumoral aspect

\section{References}

1. Chang Y, Cesarman E, Pessin MS et al (1994) Identification of herpesvirus-like DNA sequences in AIDS-associated Kaposi's sarcoma. Science 266:1865-1869

2. Di Lorenzo G, Konstantinopoulos PA, Pantanowitz L et al (2007) Management of AIDS-related Kaposi's sarcoma. Lancet Oncol 8:167-176
3. Huang L, Schnapp LM, Gruden JF et al (1996) Presentation of AIDS-related pulmonary Kaposi's sarcoma diagnosed by bronchoscopy. Am J Respir Crit Care Med 153:1385-1390

4. Kuhlman JE (1999) Imaging pulmonary disease in AIDS: state of the art. Eur Radiol 9:395-408
5. Sullivan RJ, Pantanowitz L, Casper C et al (2008) HIV/AIDS: epidemiology, pathophysiology, and treatment of Kaposi sarcoma-associated herpesvirus disease: Kaposi sarcoma, primary effusion lymphoma, and multicentric Castleman disease. Clin Infect Dis 47:1209-1215 